\title{
Prevalence, etiology, and outcome of catheterization laboratory false alarms in patients with suspected ST-elevation myocardial infarction
}

\author{
Prevalencia, causas y pronóstico de las «falsas alarmas» al laboratorio de \\ hemodinámica en pacientes con sospecha de infarto de miocardio con elevación del \\ segmento $S T$
}

Eduardo Barge-Caballero, José Manuel Vázquez-Rodríguez, Rodrigo Estévez-Loureiro, Gonzalo Barge-Caballero, Alejandro Rodríguez-Vilela, Ramón Calviño-Santos, Jorge Salgado-Fernández, Guillermo Aldama-López, Pablo Piñón-Esteban, Rosa CampoPérez, José Ángel Rodríguez-Fernández, Nicolás Vázquez-González, Javier MuñizGarcía, Alfonso Castro-Beirasa

\begin{abstract}
Introduction and objectives. To investigate the prevalence, causes and outcome of catheterization laboratory false alarms (CLFAs) in a regional primary angioplasty network.

Methods. A prospective registry of 1,662 patients referred for primary angioplasty between January 2003 and August 2008 was reviewed to identify CLFAs (i.e. when no culprit coronary lesion could be found).

Results. No culprit coronary lesion could be identified in 120 patients $(7.2 \%$; $95 \%$ confidence interval [CI], 5.9$8.5 \%)$. Of these, $104(6.3 \%, 95 \% \mathrm{CI}, 5.1-7.4 \%)$ had a discharge diagnosis other than ST-elevation myocardial infarction, 91 (5.5\%; 95\% CI, 4.3-6.6\%) had no significant coronary disease, and 64 (3.8\%; 95\% CI, 2.9-4.8\%) tested negative for cardiac biomarkers. The most frequent alternative diagnoses were: previous Q-wave myocardial infarction (18 cases), nonspecific ST-segment abnormalities (11), pericarditis (10) and transient apical dyskinesia (10). The 30-day mortality rate was similar in patients with and without culprit lesions (5.8\% vs. 5.8\%; $P=.99)$. The prevalence of CLFAs was slightly higher in patients not previously evaluated by a cardiologist and referred from emergency departments in hospitals without catheterization laboratories than in those referred by cardiologists from emergency departments at hospitals with such facilities $(9.5 \%$ vs. $6.1 \% ; P=.02$; odds ratio=1.64; $95 \%$ CI, 1.08-2.5). The prevalence of CLFAs was not significantly higher in patients referred by physicians with out-of-hospital emergency medical services $(7.2 \% ; P=.51$; odds ratio $=1.37 ; 95 \% \mathrm{CI}, 0.79-2.37)$.

Conclusions. The prevalence of CLFAs was $7.2 \%$, with the criterion of no culprit coronary lesion. Our findings suggest that different patterns of referral to catheterization laboratories could account for small variations in the prevalence of CLFAs.
\end{abstract}

Introducción y objetivos. Determinar prevalencia, causas y pronóstico de las «falsas alarmas» al laboratorio de hemodinámica (FALH) en una red regional de angioplastia primaria.

Métodos. Registro prospectivo de 1.662 pacientes remitidos para angioplastia primaria entre enero de 2003 y agosto de 2008. Se definió FALH como ausencia de lesión coronaria causal.

Resultados. En 120 pacientes (7,2\%; intervalo de confianza [IC] del 95\%, 5,9-8,5) no se identificó ninguna lesión coronaria causal. De ellos, 104 (6,3\%; IC del 95\%, 5,1-7,4) recibieron un diagnóstico alternativo a IAMCEST, 91 (5,5\%; IC del 95\%, 4,3-6,6) no presentaron enfermedad coronaria significativa y 64 (3,8\%; IC del 95\%, 2,9-4,8) presentaron marcadores de daño miocárdico negativos. Los diagnósticos alternativos más frecuentes fueron: infarto con onda Q previo (18 casos), alteraciones inespecíficas del segmento ST (11), pericarditis (10) y discinesia apical transitoria (10). La mortalidad a 30 días fue similar en los pacientes con y sin lesión causal (el 5,8 frente al 5,8\%; $\mathrm{p}=0,99$ ). La prevalencia de FALH fue discretamente superior entre los pacientes remitidos desde los servicios de urgencias de hospitales no intervencionistas sin evaluación previa por un cardiólogo que entre los remitidos por cardiólogos desde el servicio de urgencias del hospital intervencionista (el 9,5 frente al 6,1\%; $\mathrm{p}=0,02 ;$ odds ratio $[\mathrm{OR}]=1,64$; IC del 95\%, 1,08-2,5). No observamos un exceso de FALH entre los pacientes remitidos por médicos de UVI Móviles-061 (7,2\%; $\mathrm{p}=0,51 ; \mathrm{OR}=1,37$; IC del 95\%, 0,79-2,37).

Conclusiones. Hemos observado una prevalencia de FALH del 7,2\% de acuerdo con el criterio de ausencia de lesión coronaria causal. Nuestros resultados indican que diferentes modelos de activación del laboratorio de hemodinámica podrían justificar discretas variaciones en la prevalencia de FALH. 
Key words: Myocardial infarction; Angioplasty; Diagnosis; Coronary angiography

Palabras clave: Infarto de miocardio; Angioplastia; Diagnóstico; Coronariografía

Abbreviations: CHUAC, Complejo Hospitalario Universitario de A Coruña; CLFA, catheterization laboratory "false alarm"; STEMI, ST elevation myocardial infarction; OHES-061, Out-of-Hospital Emergency Service-061

\section{Introduction}

At the present time, primary angioplasty is the treatment of choice for patients with ST elevation myocardial infarction (STEMI). ${ }^{1}$ Given that the clinical benefits of the procedure depend to a large extent on the door-to-balloon time, ${ }^{2}$ the rapid recognition of the electrocardiographic findings that indicate STEMI and the immediate activation of the catheterization laboratory are of crucial importance in these patients. However, the confusion of the diagnosis with that of other entities that involve elevation of the ST segment can lead to an unnecessary emergency coronary angiography, a circumstance that increases health care costs and exposes the patient to the risks of the procedure. ${ }^{3}$

The prevalence of catheterization laboratory "false alarms" (CLFA) has been proposed as an indicator of the quality of primary angioplasty programs, ${ }^{4}$ complementary to other parameters such as door-toballoon time or mortality. Moreover, the study of the causes of CLFA provides useful information for the design of improvements in the process of candidate selection. In previous studies, the prevalence of CLFA ranged between $2.3 \%$ and $14 \%,{ }^{5-7}$ but there is little data concerning the influence on this indicator of different strategies for prehospital diagnosis and activation of the catheterization laboratory.

Our objective is to analyze the prevalence, causes and outcome of CLFA within the framework of a regional primary angioplasty network and to compare the prevalence of CLFA among 3 different models of catheterization laboratory activation.

\section{Methods}

\section{Study Context and Description}

The Interventional Cardiology Unit of Complejo Hospitalario Universitario de A Coruña (CHUAC) in northwestern Spain provides 24-hour primary angioplasty service for a population of nearly one million inhabitants, which is distributed throughout the entire Northern Area of Galicia. In this referral area, there are 4 hospitals that lack catheterization laboratories, which customarily refer patients to CHUAC for the performance of primary angioplasty.In the present article, we present an analysis of the prevalence, causes and outcome of the CLFA in the health care network of the Northern Area of Galicia during the period from January 2003 to August 2008. The information was obtained from a prospective general registry in which individual electronic data sheets were employed for the collection of demographic and clinical data, as well as information relative to the care of and complementary tests performed in all the patients referred to our center for primary angioplasty. The data concerning the vital status of patients 30 days after the procedure was obtained from the follow-up registry of the Galician health care system. All patients gave their informed consent.

\section{Protocol}

In our referral area, primary angioplasty is the reperfusion therapy recommended for all patients that come to any service of the health care system with symptoms of myocardial ischemia developing within the previous 12 hours and ST segment elevation greater than $1 \mathrm{~mm}$ in 2 contiguous leads or a new left bundle branch block if, in addition, one or more of the following criteria are present at the time of diagnosis: foreseeable delay to angioplasty $<110$ minutes, time from onset of infarction $>3$ hours, cardiogenic shock, or contraindication for fibrinolysis. The physician who establishes the diagnosis of STEMI activates the catheterization laboratory by means of direct telephone contact with the interventional cardiologist on call, who decides whether or not the procedure should be performed on the basis of the expected benefits and the comorbidity of the patient, without reviewing the electrocardiogram. During the study period, no diagnostic coronary angiography was cancelled due to reinterpretation of the electrocardiographic findings following the arrival of the patients to the catheterization laboratory. 
All the patients with suspected STEMI examined in the Emergency Service of CHUAC are immediately evaluated by the clinical cardiologist on call, who activates the catheterization laboratory once the diagnosis is confirmed. In uncertain cases, the cardiologist can perform a transthoracic or transesophageal echocardiogram if he or she considers it necessary.

In the case of the patients diagnosed as having STEMI in the emergency services of hospitals without catheterization laboratories, the responsible physician (generally the family medicine or intensive care specialist) is in charge of activating the interventional team without consulting previously with a clinical cardiologist. Then, the patient is transferred by medically equipped ambulance to the Catheterization Laboratory of CHUAC with no previous stop in the Emergency Room of the hospital.

As of May 2005, the physicians of the mobile intensive care unit of the Out-of-hospital Emergency Service 061 (OHES-061) can also activate the interventional team from any point of the referral area, and can then proceed with direct transfer of the patients with suspected STEMI to the CHUAC catheterization laboratory without stopping previously at any emergency room. All of the physicians in these units are specialists in family medicine or intensive care. Our protocol does not include the activation of the catheterization laboratory by health care technicians and, thus, all patients attended to in the out-ofhospital setting by ambulances other than mobile intensive care units of the OHES-061 are taken to the closest emergency service.

\section{Diagnostic Coronary Angiography}

All of the coronary angiographies were performed and evaluated by interventional cardiologists with recognized experience. The principal operator was responsible for determining the existence of significant coronary artery disease and identifying the coronary lesion that caused the STEMI. Significant coronary artery disease, according to visual estimation, was defined as the presence of at least one coronary stenosis occupying $>70 \%$ in at least 1 epicardial coronary artery ( $>50 \%$ in left main coronary artery). A culprit coronary lesion was defined as a total or subtotal occlusion or a stenosis $>70 \%(>50 \%$ in left main coronary artery) with a visible thrombus or other characteristics that indicated acute plaque rupture in the artery in which the STEMI had originated. Aortic angiography and left ventriculography were performed systematically in those patients in whom it was not possible to identify any culprit coronary lesion.

\section{Definition of a Catheterization Laboratory "False Alarm"}

A CLFA was defined as the impossibility of identifying any coronary lesion as the cause of the STEMI in the reference coronary angiography. The retrospective diagnoses were collected from the discharge reports and were confirmed by 2 expert cardiologists (JMVR, EBC) following an exhaustive review of the clinical records. For this purpose, the diagnostic criteria proposed by Larson et $\mathrm{al}^{5}$ were employed. A positive test for the markers of myocardial injury was defined as the presence of a troponin I peak $>0.2$ $\mathrm{ng} / \mathrm{mL}$ or a creatine kinase $\mathrm{MB}$ fraction $(\mathrm{CK}-\mathrm{MB})>7 \%$.

\section{Statistical Analysis}

Continuous variables are presented as means (standard deviation) and the categorical variables as absolute frequencies (percentages). We have employed the $\chi 2$ test for the comparison of categorical variables and Student $t$ test or ANOVA for the comparison of continuous variables. Owing to their deviation from a normal distribution, demonstrated using the Shapiro-Wilk test and P-P plots, the variables relative to delays in time are presented as the median [interquartile range] and are compared with the Mann-Whitney or Kruskal-Wallis nonparametric test. The clinical factors associated with the absence of a culprit coronary artery lesion were identified by means of backward stepwise logistic regression analysis (p-out criterion, $\mathrm{P}>$.1). The candidate variables were selected according to clinical experience and the previous literature: female sex, age <45 years, previous myocardial infarction, previous percutaneous coronary intervention, previous coronary artery surgery, absence of major cardiovascular risk factors, hemodynamic instability, left bundle branch block, and the catheterization laboratory activation model. The validity of the final model was analyzed using the test for the general significance of the coefficients, with the Hosmer-Lemeshow goodness-of-fit test and with the construction of the receiver operating characteristic (ROC) curve of the logistic regression equation. The threshold for statistical significance was set at $\mathrm{P}<.05$. All the analyses were carried out using SPSS 13.0. 


\section{Results}

Between January 2003 and August 2008, 1662 patients with suspected STEMI were referred to the catheterization laboratory of CHUAC for the performance of primary angioplasty. Of these, 948 (57\%) were sent from the emergency service of that same hospital (ES-CHUAC group), 451 (27.1\%) came from the emergency services of hospitals lacking catheterization laboratories (ES-others group) and 263 (15.9\%) were transported from the out-of-hospital setting by mobile intensive care units of the OHES 061 (OHES-061 group). Table 1 shows the baseline characteristics of patients included in the study.

Table 1. Baseline characteristics of the patients included in the study

\begin{tabular}{|c|c|c|c|c|}
\hline Age, mean (SD), y & $64(12.9)$ & $65.2(13.6)$ & $62.3(12.3)$ & .04 \\
\hline Hypertension, n (\%) & $349(36.8)$ & $167(37)$ & $98(37.3)$ & .99 \\
\hline Hypercholesterolemia, n (\%) & $311(32.8)$ & $120(26.6)$ & $92(35)$ & .03 \\
\hline Diabetes mellitus, $\mathrm{n}(\%)$ & $150(15.8)$ & $85(18.8)$ & $40(15.2)$ & .3 \\
\hline Previous myocardial infarction, $\mathrm{n}(\%)$ & $127(13.4)$ & $57(12.6)$ & $18(6.8)$ & .01 \\
\hline Previous PCI, n (\%) & $118(12.4)$ & $43(9.5)$ & $19(7.2)$ & .03 \\
\hline Previous coronary artery surgery, n (\%) & $24(2.5)$ & $11(2.4)$ & $4(1.5)$ & .63 \\
\hline Hemodynamic instability, $\mathrm{n}(\%)^{\mathrm{a}}$ & $66(7)$ & $34(7.5)$ & $12(4.6)$ & .28 \\
\hline Left bundle branch block, n (\%) & $28(3)$ & $18(4)$ & $6(2.3)$ & .4 \\
\hline Infarction site, $\mathrm{n}(\%)^{\mathrm{b}}$ & & & & .22 \\
\hline
\end{tabular}

ES-CHUAC indicates Emergency Services of Complejo Hospitalario Universitario de A Coruña; ES-others, emergency services of hospitals lacking catheterization laboratories; OHES-061, out-of-hospital emergency services; PCI, percutaneous coronary intervention; SD, standard deviation.

${ }^{a}$ Shock of any origin or persistent hypertension requiring infusion of inotropic agents or insertion of an intraaortic balloon co unterpulsation device.

${ }^{\mathrm{b}}$ According to the criteria of the physician who activates the catheterization laboratory

\section{Prevalence of "False Alarms"}

No culprit coronary lesion was identified in 120 patients (7.2\%; 95\% confidence interval [CI], 5.9-8.5). Of these, $104(86.7 \%)$ received a diagnosis other than STEMI at discharge and 64 (53.3\%) tested negative for markers of myocardial injury (Figure 1). Thus, the prevalence of patients with an alternative diagnosis was $6.3 \%$ (95\% CI, 5.1-7.4) and the prevalence of patients with no culprit coronary lesion and testing negative for markers of myocardial injury was 3.8\% (95\% CI, 2.9-4.8); 91 patients $(5.5 \%$; 95\% CI, $4.3-$ 6.6) were characterized by the absence of significant coronary artery disease. The final diagnoses in patients with no culprit lesion are shown in Table 2.

Of the 1542 patients $(92.8 \%)$ in whom some type of culprit coronary lesion was identified, 1494 $(89.9 \%)$ were treated with primary angioplasty, $12(0.7 \%)$ with coronary revascularization surgery and 36 $(2.2 \%)$ received medical treatment. In all, primary angioplasty was not attempted in 168 patients $(10.1 \%$; 95\% CI, 8.6-11.6) 


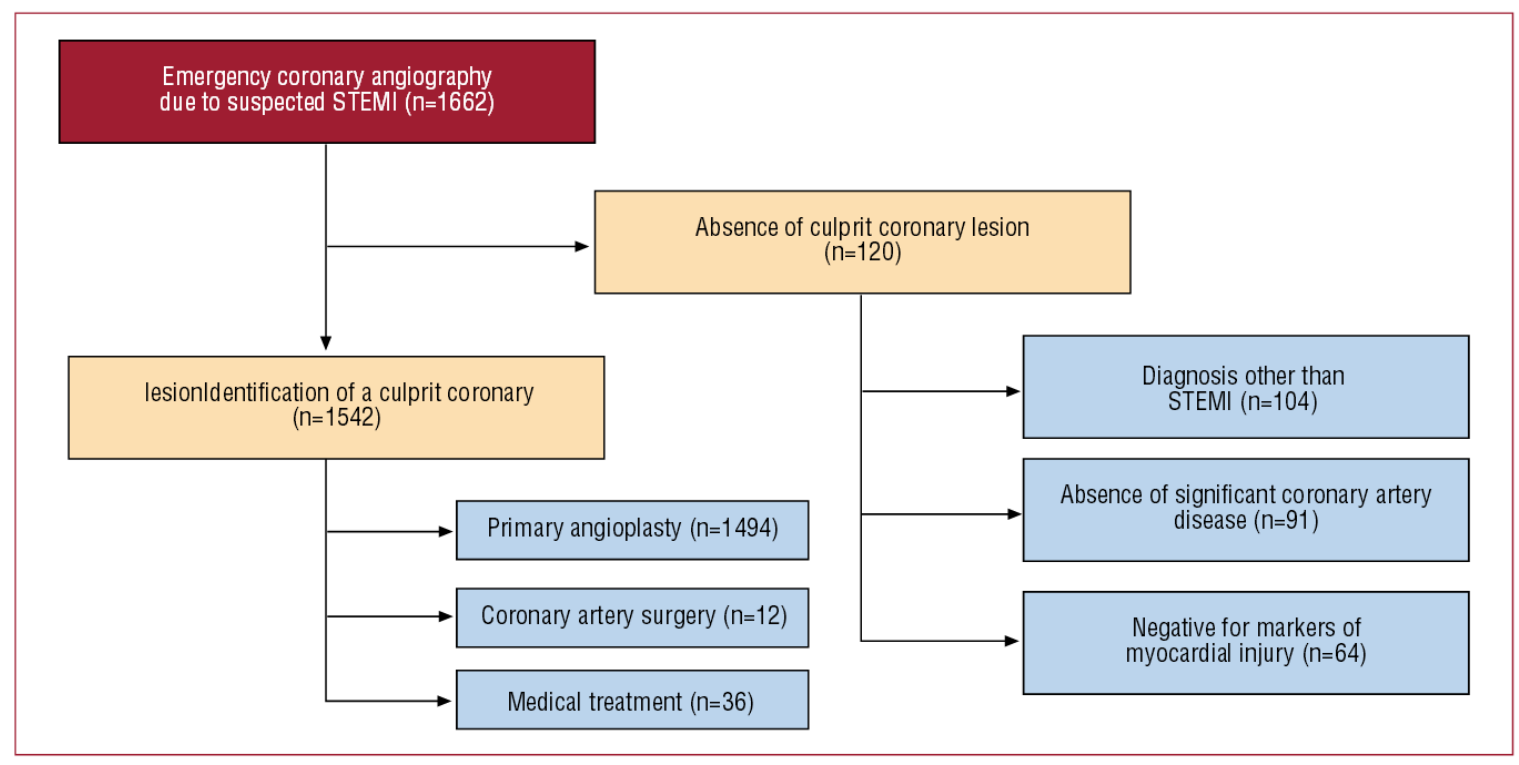

Figure 1. Flow chart corresponding to the study. STEMI indicates ST elevation myocardial infarction.

Table 2. Final diagnoses in the patients with no culprit coronary lesion $(n=120)$

\begin{tabular}{|c|c|}
\hline Diagnosis & Patients, No. \\
\hline \multicolumn{2}{|l|}{ Cardiovascular disease $(\mathrm{n}=72 ; 60 \%)$} \\
\hline STEMI with no culprit coronary lesion & 16 \\
\hline Pericarditis & 10 \\
\hline Transient apical dyskinesia & 10 \\
\hline Coronary spasm & 9 \\
\hline Myocarditis & 9 \\
\hline Aortic dissection & 4 \\
\hline Non-Q-wave myocardial infarction & 3 \\
\hline Severe aortic stenosis & 3 \\
\hline Unstable angina & 2 \\
\hline Pulmonary thromboembolism & 1 \\
\hline Severe aortic insufficiency & 1 \\
\hline Pericardial hematoma & 1 \\
\hline Hypertensive crisis & 1 \\
\hline Idiopathic dilated cardiomyopathy & 1 \\
\hline Cocaine-induced cardiomyopathy & 1 \\
\hline \multicolumn{2}{|c|}{ Isolated electrocardiographic changes $(n=38 ; 32 \%)$} \\
\hline Previous Q-wave infarction & 18 \\
\hline Nonspecific ST segment changes & 11 \\
\hline Left bundle branch block & 5 \\
\hline Early repolarization & 1 \\
\hline Hyperkalemia & 1 \\
\hline Atrioventricular block & 1 \\
\hline Left ventricular hypertrophy & 1 \\
\hline \multicolumn{2}{|l|}{ Noncardiovascular disease $(n=9 ; 7 \%)$} \\
\hline Bacterial pneumonia & 3 \\
\hline Acute cholecystitis & 2 \\
\hline Intestinal ischemia & 1 \\
\hline Cholangitis & 1 \\
\hline Diverticulitis & 1 \\
\hline Esophageal perforation & 1 \\
\hline Unknown $(\mathrm{n}=1 ; 1 \%)$ & 1 \\
\hline
\end{tabular}

STEMI indicates ST elevation myocardial infarction. 


\section{Clinical Profile and Prognosis of the "False Alarms"}

Patients without a culprit coronary lesion were younger and presented a higher incidence of hemodynamic instability and a history of myocardial infarction and previous percutaneous coronary intervention than those patients in which a culprit lesion was identified (Table 3). The median time interval between the onset of symptoms and coronary angiography was 246 [254] minutes in patients without a culprit lesion and 217 [206] minutes in those with a culprit lesion $(P=.02)$. Table 3 shows that all the time intervals were longer in the patients without a culprit lesion.

Table 3. Clinical Features and Time to Coronary Angiography According to the Presence or Absence of a Culprit Coronary Lesion

\begin{tabular}{|c|c|c|c|}
\hline & Without Culprit Lesion $(n=120)$ & With Culprit Lesion $(\mathrm{n}=1542)$ & $P$ \\
\hline Age, mean (SD), y & $60.7(15.2)$ & $63.3(12.7)$ & .03 \\
\hline Women, $\mathrm{n}(\%)$ & $30(25)$ & $286(18.5)$ & .08 \\
\hline Hypertension, n (\%) & $49(40.8)$ & $565(36.6)$ & .36 \\
\hline Hypercholesterolemia, n (\%) & $39(32.5)$ & $484(31.4)$ & .8 \\
\hline Diabetes mellitus, $\mathrm{n}(\%)$ & $14(11.7)$ & $261(16.9)$ & .13 \\
\hline Smoker or ex-smoker, n (\%) & $45(37.5)$ & $704(45.7)$ & .08 \\
\hline Previous myocardial infarction, n (\%) & $31(25.8)$ & $171(11.1)$ & $<.001$ \\
\hline Previous PCI, n (\%) & $21(17.5)$ & $159(10.3)$ & .01 \\
\hline Previous coronary artery surgery, n (\%) & $4(3.3)$ & $35(2.3)$ & .46 \\
\hline Hemodynamic instability, $\mathrm{n}(\%)^{\mathrm{a}}$ & $14(11.7)$ & $98(6.4)$ & .02 \\
\hline Left bundle branch block, n (\%) & $11(9.2)$ & $41(2.7)$ & $<.001$ \\
\hline Infarction site, $\mathrm{n}(\%)^{\mathrm{b}}$ & & & $<.001$ \\
\hline Anterior/wall & $60(50)$ & $666(43.2)$ & \\
\hline Inferior/posterior & $37(30.8)$ & $766(49.7)$ & \\
\hline Lateral & $11(9.2)$ & $64(4.2)$ & \\
\hline Undetermined & $12(10)$ & $46(3)$ & \\
\hline \multicolumn{4}{|l|}{ Delays, min [interquartile range] } \\
\hline Pain onset to first health care contact & $148[168]$ & 115 [147] & .03 \\
\hline First contact to coronary angiography & $122[95]$ & $90[72]$ & $<.001$ \\
\hline First contact to laboratory activation & $49[55]$ & $25[38]$ & $<.001$ \\
\hline Pain onset to coronary angiography & $246[254]$ & $217[206]$ & .02 \\
\hline
\end{tabular}

PCI indicates percutaneous coronary intervention; SD, standard deviation.

a Shock of any origin or persistent hypertension requiring infusion of inotropic agents or insertion of an intraaortic balloon counterpulsation device.

${ }^{\mathrm{b}}$ According to the criteria of the physician who activates the catheterization laboratory.

The 30-day mortality rate was $5.8 \%(P=.99)$ in both groups. The causes of death among patients with no culprit lesion were septic shock $(n=3$; pneumonia, cholangitis, and purulent pericarditis secondary to esophageal perforation), cardiogenic shock $(\mathrm{n}=2$; severe aortic stenosis and chronic ischemic cardiomyopathy), and aortic dissection $(n=2)$. None of these deaths was directly attributable to complications of coronary angiography

\section{Subgroups With a Greater Prevalence of "False Alarms"}

Multivariate analysis revealed a statistically significant association between female sex, age <45 years, left bundle branch block, previous myocardial infarction, and activation of the catheterization laboratory from emergency services of centers lacking catheterization laboratories with no previous evaluation by a cardiologist and the incidence of CLFA (Table 4). The association between the absence of cardiovascular risk factors and CLFA was on the borderline of statistical significance $(\mathrm{P}=.06)$. The validity of the model was corroborated by the Hosmer-Lemeshow goodness-of-fit test $(\chi 2=4.3 ; \mathrm{P}=.74)$ and by the test for the general significance of the coefficients $(\chi 2=49.9 ; \mathrm{P}<.001)$. The ROC curve of the logistic regression model revealed a moderate predictive capacity $(\mathrm{AUC}=0.67 ; \mathrm{P}<.001)$. 
Table 4.Clinical Factors Associated With absence of a Culprit Coronary Lesion: Multivariate Analysis

\begin{tabular}{|c|c|c|}
\hline Age $<45$ years & $2.57(1.49-4.41)$ & .01 \\
\hline Previous myocardial infarction & $3.11(1.97-4.9)$ & $<.001$ \\
\hline Left bundle branch block & $3.46(1.69-7.11)$ & .01 \\
\hline Absence of major cardiovascular risk factors ${ }^{a}$ & $1.47(0.99-2.21)$ & .06 \\
\hline ES-others & $1.64(1.08-2.5)$ & .02 \\
\hline OHES-061 & $1.37(0.79-2.37)$ & 0.26 \\
\hline
\end{tabular}

indicates confidence interval; ES-others, emergency services of hospitals lacking catheterization laboratories; OHES-061, out-ofhospital emergency services; OR, odds ratio.

${ }^{a}$ Absence of a history of hypertension, diabetes mellitus, smoking habit, or dyslipidemia.

${ }^{b}$ For this variable, the reference category is the group of patients referred by cardiologists from the emergency service of the intervention center.

\section{Models of Catheterization Laboratory Activation}

The prevalence of an absence of a culprit coronary lesion was significantly higher in the ES-others group (9.5\%; 95\% CI, 7.8-14.4) than in the ES-CHUAC group (6.1\%;95\% CI, 4.5-7.7; $\mathrm{P}=.021)$, but no significant difference was observed between this group and the OHES-061 group (7.2\%; 95\% CI, 3.9$10.5 ; \mathrm{P}=.51)$. The ES-others group had the highest prevalence of patients with a diagnosis other than STEMI, with absence of significant coronary artery disease, and with absence of a culprit coronary lesion and testing negative for markers of myocardial injury (Figure 2). Considering the ES-CHUAC group as the category of reference, the odds ratios (OR) of the absence of a culprit lesion adjusted for the variables included in the logistic regression model were $\mathrm{OR}=1.64(95 \% \mathrm{CI}, 1.08-2.5)$ for the ES-others group and $\mathrm{OR}=1.37$ (95\% CI, 0.79-2.37) for the OHES-061 group (Table 4).

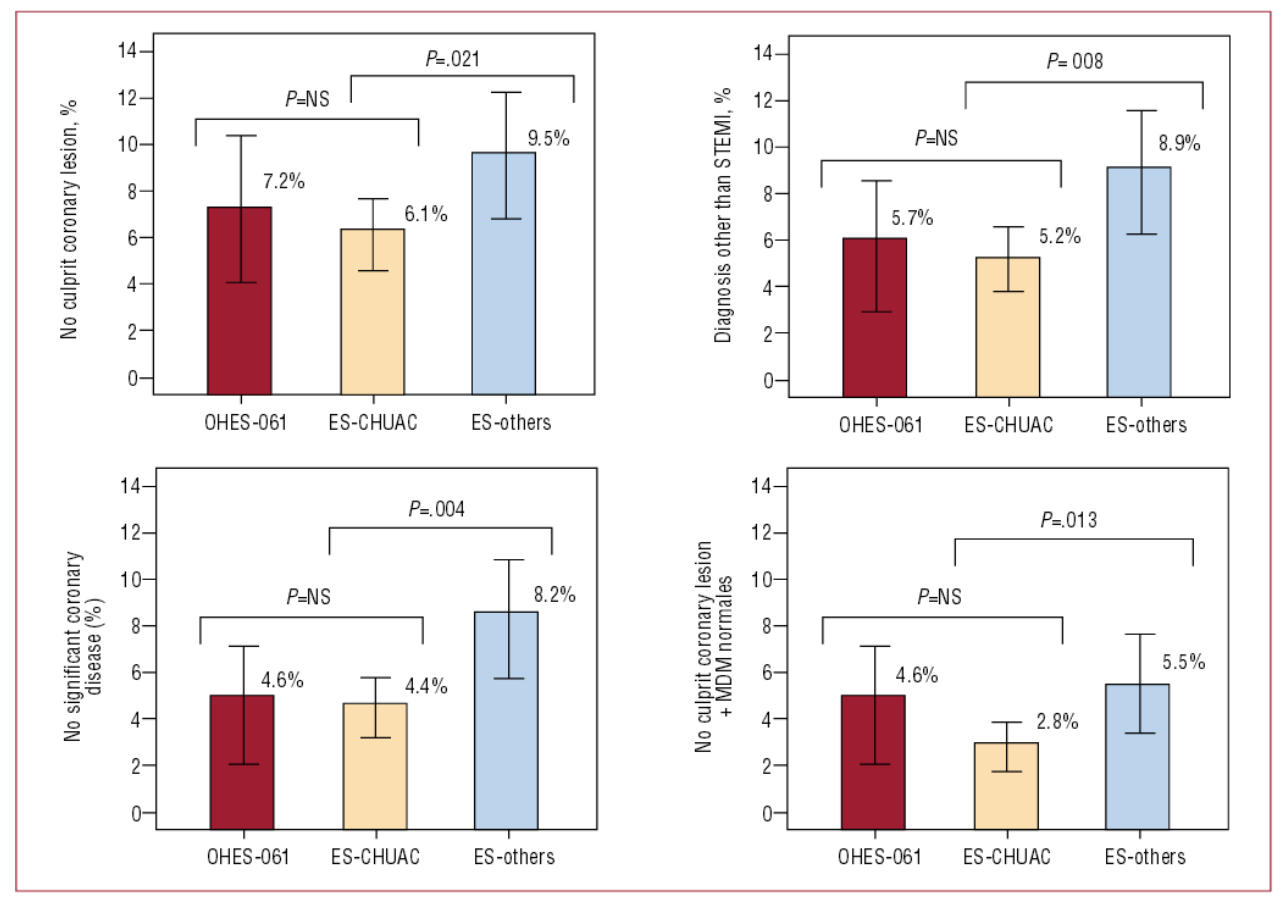

Figure 2. Prevalence of "false alarms" with three different models of catheterization laboratory activation. ES-CHUAC indicates Emergency Services of

Complejo Hospitalario Universitario de A Coruña; ES-others, emergency services of hospitals lacking catheterization laboratories; MIM, myocardial injury markers; NS, not significant; OHES-061, out-of-hospital emergency services; STEMI, ST elevation myocardial infarction. 


\section{Discussion}

\section{Prevalence of "False Alarms"}

In this prospective registry of 1662 patients referred for primary angioplasty between January 2003 and August 2008, the prevalence of CLFA was $7.2 \%$, based on the criterion of no culprit coronary lesion according to the reference coronary angiogram. At the present time, it is understood that the broadening of the indications for primary angiography may lead to an increase in the proportion of CLFA, ${ }^{8}$ but there is a lack of agreement as to what values should be considered unacceptable. The prevalence of CLFA observed in our series does not appear to be excessive since it is along the lines of that of other systems similar to our setting. The wide variability in the prevalence of CLFA reported in previous studies (between $2.3 \%$ and $14 \% 3,^{5-7}$ ) reflects regional differences in the quality of the selection systems, but is also influenced by the heterogeneity of the criteria for the selection of candidates for primary angioplasty and the diversity of the models for diagnosis and prehospital activation of the catheterization laboratory.

Another circumstance that complicates the comparison of the results from one study to another is the use of different criteria to define the CLFA. Despite the fact that the majority of the reports have considered only angiographic criteria, the existence of STEMI in the absence of coronary lesions has been reported to be a result of mechanisms that include spontaneous coronary recanalization, coronary embolism or coronary spasm. ${ }^{9}$ In our series, 16 patients with no culprit coronary lesion received a retrospective diagnosis of STEMI at discharge. If we exclude these cases, the "true" prevalence of CLFA (that is, patients with a diagnosis other than STEMI) is reduced to 6.3\%. It is interesting to note that $38 \%$ of the patients in this subgroup tested positive for the markers of myocardial injury, a data that reflects the lack of specificity of said determination for the diagnosis of STEMI. It is common to observe an elevation of the markers of myocardial injury in patients with myocarditis, pericarditis, congestive heart failure, renal failure or sepsis. ${ }^{10}$

\section{Clinical Implications}

In order to minimize the delay until reperfusion, the activation of the catheterization laboratory should take place as soon after the recognition of the electrocardiographic findings indicating STEMI as possible in a patient with symptoms of acute myocardial ischemia, without the aid of other complementary studies such as an echocardiogram or markers of myocardial injury. Under these circumstances, the differential diagnosis between STEMI and other causes of ST segment elevation ${ }_{1}$ may prove to be difficult. Thus, primary angioplasty programs must assume that a certain proportion of CLFA is inevitable, as occurs with other procedures in which the delay in therapy is a fundamental prognostic factor (for example, emergency laparotomy in patients with suspected appendicitis).

The activation of the catheterization laboratory is completely justified in most cases of CLFA. ${ }^{12,13}$ As in other studies, ${ }^{5,6}$ the majority of the CLFA in our series were the consequence of an erroneous interpretation of the baseline electrographic changes (such as previous myocardial necrosis, nonspecific abnormalities in the ST segment or left bundle branch block) or of confusion with other low risk cardiovascular disorders that involve ST segment elevation (pericarditis, myocarditis, transient apical dyskinesia). In many of these cases, it is reasonable to perform coronary angiography if doubts concerning the diagnosis persist, since the risks associated with the procedure are low ${ }^{13}$ and usually do not surpass the severity of the consequences of not identifying a developing STEMI ${ }^{14}$ or of administrating fibrinolytics to a patient with another disease.15Despite these considerations, we should point out the fact that a small proportion of CLFA cases involved patients who presented life-threatening diseases such as aortic dissection, septic shock or acute abdominal processes. The severity of this underlying problem explains the fact that the 30-day mortality rate was similar to that of the patients with a culprit lesion. Recently, Gu et al observed a 30-day mortality rate of $16 \%$ in cases of CLFA, and attributed this finding to a range of high risk diseases similar to that reported in our study.

It is precisely in the patients with a severe alteration of their general status in whom we must do our utmost to make no mistakes with respect to the diagnosis of STEMI in order to avoid adverse consequences derived from a CLFA. Although the majority of these patients benefit from the emergency transfer to a tertiary level hospital, the performance of an unnecessary coronary angiogram can have an unfavorable prognostic impact in some cases, due both to the increase in the delay until proper treatment is provided and to the exposure to the risk of contrast-induced nephropathy and of bleeding in association with antithrombotic drugs. Thus, it would appear to be reasonable that the initial diagnostic approach in a critically ill patient with inconclusive electrocardiographic findings include the performance of noninvasive cardiovascular tests such as echocardiography or computed tomography angiography prior to 
the activation of the catheterization laboratory, although this approach could result in a slight increase in the delay to reperfusion in those cases in which the diagnosis of STEMI is ultimately confirmed.

It is interesting to note that the delay between the onset of symptoms and the first contact with the health care system and the interval between the latter and coronary angiography were longer in the cases of CLFA than in the patients with STEMI. The explanation for this finding may be the fact that, in the cases of CLFA, it is more difficult for the patient to recognize the symptoms and that the physician in charge has greater doubts with respect to the suitability of catheterization laboratory activation.

\section{Groups in Which the Prevalence of "False Alarms" is High}

In our series, we have identified several subgroups of patients with an elevated prevalence of CLFA. One of them is made up of individuals under 45 years of age, probably because of their low risk for coronary artery disease and the fact that some entities, such as pericarditis, myocarditis and variants of ST segment normality, are more common in young patients. CLFA was also more prevalent among women, probably in relation to a high frequency of atypical clinical presentation and of transient apical dyskinesia. The marked incidence of CLFA among patients with previous myocardial infarction or left bundle branch block is explained by the difficulty in interpreting the electrocardiographic findings when there are baseline repolarization changes. Given that, in clinical practice, it is difficult to have access to a previous tracing with which to compare, ${ }^{6}$ it may be useful to give a copy of a recent electrocardiogram to all patients with cardiovascular disease at the time of their hospital discharge.

In any case, the analysis of the ROC curve indicates that the capacity of the logistic regression model to predict the occurrence of CLFA is low (area under the curve [AUC] $=0.67$ ). The wide variability not explained by the model indicates the existence of other factors, in many cases circumstantial and difficult to measure, that would play a role in the occurrence of a CLFA in routine clinical practice.

\section{Models for Catheterization Laboratory Activation}

In our study, the prevalence of CLFA in the group of patients referred from emergency services of hospitals lacking catheterization laboratories with no previous consultation with a cardiologist was $9.5 \%$. This incidence is similar to that reported in previous studies ${ }^{5,6}$ and represents an absolute increase of $3.4 \%$ with respect to that observed in the group of patients referred from the emergency service of the hospital that is equipped with a catheterization laboratory, where all the cases were evaluated by the clinical cardiologist on call prior to catheterization laboratory activation. This finding can be justified in part by the greater skill of the cardiologist in interpreting changes in the ST segment, ${ }^{16}$ but also by his or her ability to perform an echocardiogram to support the diagnosis when the electrocardiogram is inconclusive. In any case, given that the activation of the catheterization laboratory by emergency physicians has made it possible to significantly reduce the door-to-balloon time, ${ }^{17}$ the slight increase observed in the proportion of CLFA does not appear to be enough to justify the systematic evaluation of all patients with STEMI by a cardiologist prior to catheterization laboratory activation. This option could lead to an unnecessary delay in those patients with conclusive electrocardiographic findings. Thus, we consider that it should be reserved exclusively for the uncertain cases.

The direct transfer of patients with STEMI from the out-of-hospital setting to the catheterization laboratory by OHES ambulances is another effective strategy for reducing the door-to-ballon time. ${ }^{18}$ In our study, the activation of the catheterization laboratory by physicians of the mobile intensive care unit of the OHES-061 was associated with a low prevalence of CLFA (7.2\%), a fact that supports the model involving direct transferal as a reasonable option to facilitate the rapid access of patients with an out-ofhospital diagnosis of STEMI to primary angioplasty.

\section{Limitations}

The retrospective analysis of the alternative diagnoses has shown that, in some cases, they are purely presumptive. Moreover, it could be that the analysis of the influence of the different models of catheterization laboratory activation on the prevalence of CLFA is subject to selection bias, given the nonrandomized, observational design of the study. For this reason, the results should be considered only as a starting point for the generation of hypotheses that will need to be confirmed in future studies. The external validity of this analysis is not guaranteed either and, thus, the conclusions may prove to be irreproducible in other health care systems. Finally, the lack of information concerning the number of patients with STEMI who did not undergo reperfusion therapy has impeded us from analyzing the diagnostic sensitivity of the different models of catheterization laboratory activation. 


\section{Conclusions}

In brief, in our series, we have observed a prevalence of CLFA of $7.2 \%$ according to the criterion of no culprit coronary lesion, which would be reduced to $6.3 \%$ if we were to consider only those cases in which there was a retrospective diagnosis other than STEMI. Moreover, we have identified a series of factors associated with a higher prevalence of CLFA, such as female sex, age less than 45 years, left bundle branch block and previous myocardial infarction. Although the majority of the cases of CLFA could be attributed to baseline abnormalities in the electrocardiogram or to low risk cardiovascular disease (myocarditis, pericarditis, transient apical dyskinesia), a small proportion of patients had some lifethreatening underlying disease (such as aortic dissection, septic shock or acute abdominal processes). Finally, our results indicate that the use of different models of catheterization laboratory activation can lead to slight variations in the prevalence of CLFA, but they will need to be corroborated in future studies

\section{References}

1. F. van de Werf, J. Bax, A. Betriu, C. Blomstrom-Lundqvist, F. Crea, V. Falk, et al. Guía de práctica clínica de la Sociedad Europea de Cardiología (ESC). Manejo del infarto agudo de miocardio en pacientes con elevación persistente del segmento ST Rev Esp Cardiol, 62 (2009), pp. e1-e47

2. S. Mingo, J. Goicolea, L. Nombela, E. Sufrate, A. Blasco, I. Millán, et al. Angioplastia primaria en nuestro medio. Análisis de los retrasos hasta la reperfusión, sus condicionantes y su implicación pronóstica Rev Esp Cardiol, 62 (2009), pp. 15-22

3. Y.L. Gu, T. Svilaas, I.C. van der Horst, F. Zijlstra Conditions mimicking acute ST-segment elevation myocardial infarction in patients referred for primary percutaneous coronary intervention Neth Heart J, 16 (2008), pp. 325331

4. F.A. Masoudi, R.O. Bonow, R.G. Brindis, C.P. Cannon, J. DeBuhr, S. Fitzgerald, et al. AHA/ACC 2008 Statement for Performance Measurement and Reperfusion Therapy: a Report of the AHA/ACC Task Force of Performance Measurements (Work Group to Address the Challenges on Performance Measurements and Reperfusion Therapy) J Am Coll Cardiol, 52 (2008), pp. 2100-2112

5. D.M. Larson, K.M. Menssen, S.W. Sharkey, S. Duval, R.S. Schwartz, J. Harris, et al. "False-positive" cardiac catheterization laboratory activation among patients with suspected ST-segment elevation myocardial infarction JAMA, 298 (2007), pp. 2754-2760

6. S.B. Prasad, D.A. Richards, N. Sadick, A.T.L. Ong, P. Kovoor Clinical and electrocardiographic correlates of normal coronary angiography in patients referred for primary percutaneous coronary intervention Am J Cardiol, 102 (2008), pp. 155-159

7. P. Widimsky, B. Stellova, L. Groch, M. Aschermann, M. Branny, M. Zelizko, et al. Prevalence of normal coronary angiography in the acute phase of suspected ST-elevation myocardial infarction: experience from the PRAGUE studies Can J Cardiol, 22 (2006), pp. 1147-1152

8. W.J. van der Giessen Primary PCI: false positives versus false negatives Neth Heart J, 16 (2008), pp. 323-324

9. J.S. Alpert Myocardial infarction with angiographically normal coronary arteries Arch Intern Med, 154 (1994), pp. 265-269

10. C. Roongsritong, I. Warraich, C. Bradley Common causes of troponin elevation in the absence of acute myocardial infarction: incidence and clinical significance Chest, 125 (2004), pp. 1877-1884

11. K. Wang, R.W. Asinger, H.J.L. Marriot ST-segment elevation in conditions other than acute myocardial infarction N Engl J Med, 349 (2003), pp. 2128-2135

12. A.T. Yan, R.T. Yan, S.G. Goodman Misinterpretation of electrocardiograms and cardiac catheterization laboratory activations JAMA, 299 (2008), p. 1897

13. F.A. Masoudi Measuring the quality of primary PCI for ST-segment elevation myocardial infarction: time for balance JAMA, 298 (2007), pp. 2790-2791

14. F.A. Masoudi, D.J. Magid, D.R. Vinson, A.J. Tricomi, E.E. Lyons, L. Crounse, et al. Implications of the failure to identify high-risk electrocardiogram findings for the quality of care of patients with acute myocardial infarction: results of the Emergency Department Quality in Myocardial Infarction (EDQMI) study Circulation, 114 (2006), pp. $1565-1571$

15. N.E. Khoury, S. Borzak, A. Gloki, S. Havstad, S.T. Smith, M. Jones "Inadverted" thrombolytic administration in patients without myocardial infarction: clinical features and outcome Ann Emerg Med, 28 (1996), pp. 289-293

16. S.D. Turnipseed, A.E. Bair, J.D. Kirk, D.B. Diercks, P. Tabar, E.A. Amsterdam Electrocardiogram differentiation of benign early repolarization versus acute myocardial infarction by emergency physicians and cardiologists Acad Emerg Med, 13 (2001), pp. 961-966

17. U.N. Khot, M.L. Johnson, C. Ramsey, M.B. Khot, R. Todd, S.R. Shaikh, et al. Emergency department physician activation of the catheterization laboratory and immediate transfer to an immediately available catheterization laboratory reduce door-to-balloon time in ST-elevation myocardial infarction Circulation, 116 (2007), pp. 67-76

18. M.R. Le May, D.Y. So, R. Dionne, C.A. Glover, M.P. Froeschl, G.A. Wells, et al. A city-wide protocol for primary PCI in ST-segment elevation myocardial infarction N Engl J Med, 358 (2008), pp. 231-240 